\title{
Alkaloids in Processed Rhizoma Corydalis and Crude Rhizoma Corydalis Analyzed by GC/MS
}

\author{
Zhifeng Guo, Ru Cai, Huidan Su, and Yunlong Li \\ Key Laboratory of Medical Chemistry and Molecular Diagnosis, College of Chemistry and Environmental Science, Hebei University, \\ Baoding 071002, China
}

Correspondence should be addressed to Zhifeng Guo; gzfvg@hbu.edu.cn

Received 3 June 2014; Accepted 2 August 2014; Published 25 August 2014

Academic Editor: Sibel A. Ozkan

Copyright (C) 2014 Zhifeng Guo et al. This is an open access article distributed under the Creative Commons Attribution License, which permits unrestricted use, distribution, and reproduction in any medium, provided the original work is properly cited.

The alkaloids in the processed Rhizoma Corydalis and the crude Rhizoma Corydalis were qualitatively and semiquantitatively analyzed using gas chromatography-mass spectrometry (GC/MS) method. The processing herb drug procedure was carried out according to the standard method of Chinese Pharmacopoeia. The samples were extracted using Soxhlet extractor with different solvents: methanol and acetone. The extraction effect on different solvents was investigated. The results showed that 11 kinds of alkaloids were identified from the crude Rhizoma Corydalis and only two were from the processed Rhizoma Corydalis. A total of 13 kinds of alkaloids were all based on two backbones. The alkaloids in the processed sample were less than those in the crude Rhizoma Corydalis significantly, while almost the corydaline has been changed in conformation after the sample had undergone processing, which provided support for the conclusion of reducing toxicity when the herbal medicine having been undergone a traditional drugs treatment process.

\section{Introduction}

Rhizoma Corydalis (RC), belonging to Corydalis species and the family of Papaveraceae, is a perennial herbaceous plant and grows mostly in Northeastern China. The tubers of RC have been employed as analgesic, sedative, and hypnagogue for long times $[1,2]$, which is a well-known traditional Chinese herbal medicine, Corydalis yanhusuo W.T. Wang and acts against myocardial ischemia, gastric ulcer, and tumour in the medical field. The bioactive constituents, corydaline, have analgesic efficacy but little toxicity [3-6].

The crude RC were used as samples in all phytochemical analysis, but the RC as traditional Chinese medicine often underwent processing. There is an old saying in China: "As a medicine, it is somewhat toxic," so the folk pharmacists always make the natural herbal medicine a processing handcraft to enhance efficiency and reduce toxicity. It has been reported that more than 20 kinds of alkaloids are identified in RC [7-9], which have the similar biosynthetic route and backbone to berberine $[10,11]$. These alkaloids are formed from two molecules of tyrosine. The tyrosines bioassemble the benzylisoquinolines, while the more immediate, pose the berberine basic structure [12]. The characteristics of these alkaloids are higher boiling points and lower vapor pressures. Thin-layer chromatography (TLC), high performance liquid chromatography (HPLC) [13-15], high performance capillary electrophoresis (HPLE) [16], and supercritical fluid chromatography [17] were often employed in the analysis of these alkaloids. Liquid chromatography-mass spectrometry (LC/MS) and multistage spectrometry $\left(\mathrm{MS}^{n}\right)$ were also reported in some literatures [18-20]. However, identified alkaloids are uneasy using LC/MS due to no available mass spectral database on electrospray ionization (ESI). GC/MS is one of the highest sensitivity analysis techniques, whose limit of detection can easily reach picogram $\left(10^{-12}\right)$ and provide available standard mass spectral data library [21-23].

In this paper, the processed RC was employed as sample to investigate whether the alkaloids content and composition were changed. The crude $\mathrm{RC}$ was processed according to the standard method of Chinese Pharmacopoeia compiled by Pharmacopoeia Commission of Ministry of the Health of China as processed RC sample [24]. The processed RC 


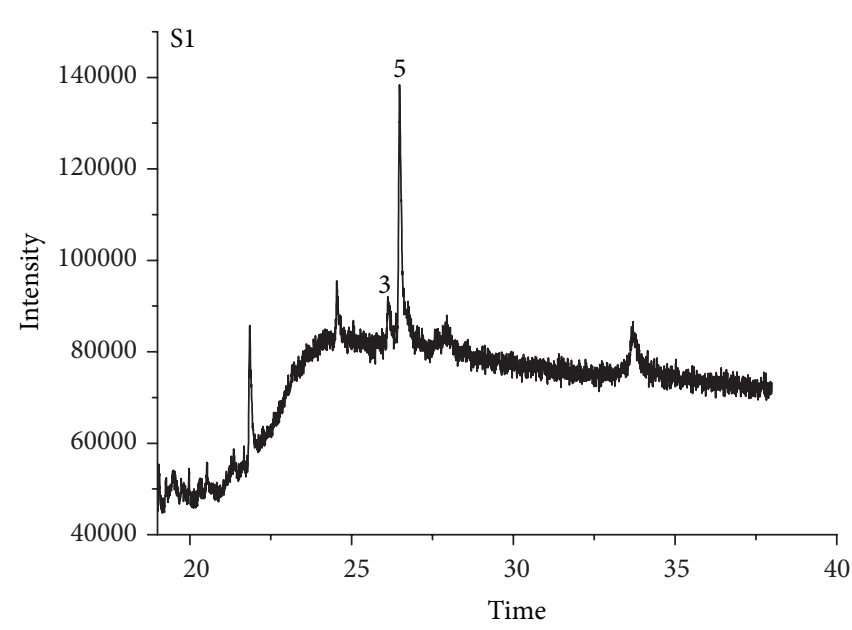

(a)

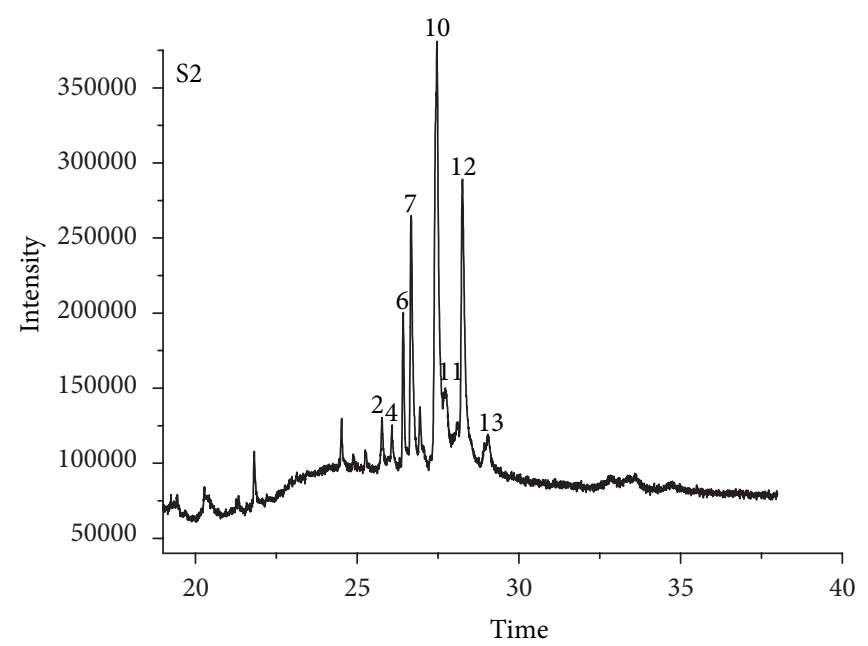

(b)

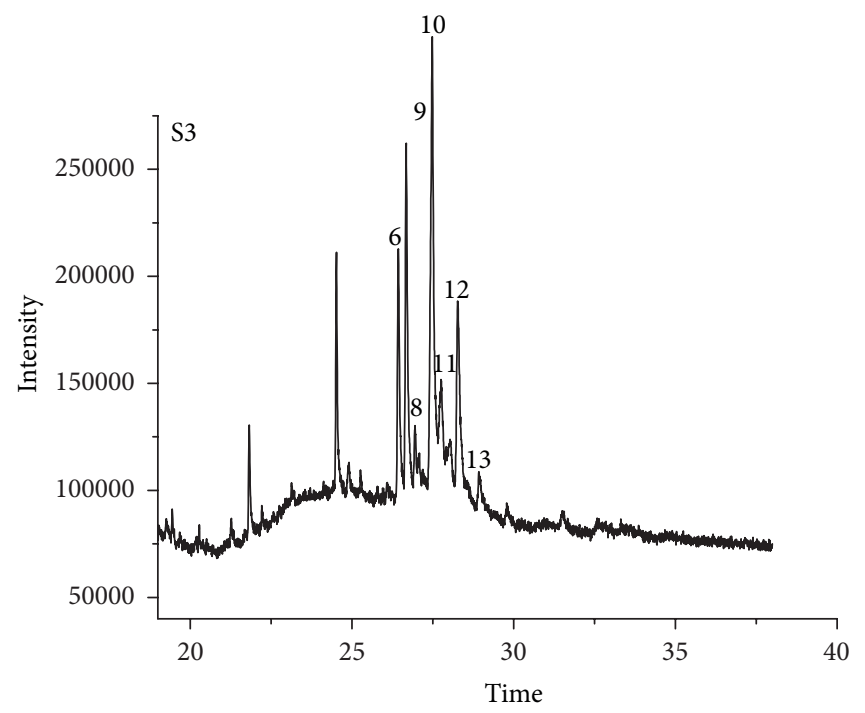

(c)

FIGURE 1: Total ion current chromatograms of RC. S1: processed RC sample extracted with methanol, S2: crude RC sample extracted with methanol, and S3: crude RC sample extracted with acetone. (a) The total chromatogram and (b) the enlarged chromatogram after 19 min. The peak number is consistent with Table 1. $4 \#$ and 5\# (+)-corydaline. Column: HP-5-MS column, injector temperature: $260^{\circ} \mathrm{C}$, GC oven temperature program: $40^{\circ} \mathrm{C}$ (does not hold), at $40^{\circ} \mathrm{C} / \mathrm{min}$ to $110^{\circ} \mathrm{C}$ (does not hold), at $8^{\circ} \mathrm{C} / \mathrm{min}$ to $260^{\circ} \mathrm{C}$ (holds for $10 \mathrm{~min}$ ).

samples were extracted in Soxhlet extractor with methanol, and the crude RC sample, as control, was extracted with two different solvents, methanol and acetone. A comparison of the differences and similarities between the processed $\mathrm{RC}$ and the crude RC on the alkaloids was performed for both qualitative and semiquantitative analyses.

\section{Experiment}

2.1. Reagents. The plant materials were provided from Traditional Chinese Medicine Institute of Heibei University and authenticated by pharmacist Xianmao Liang. A voucher specimen has been deposited in our laboratory. The chemicals purchased from a local chemical company (Hua Xin, Baoding, China) were of analytical reagent grade and included methanol (MeOH), acetone (Ac), dichloromethane, and sodium hydroxide. Acetic acid and hydrochloric acid $(12 \mathrm{~mol} / \mathrm{L})$ were also purchased from the local chemical company. The water used in the experiments was doubly distilled and prepared in our laboratory.

2.2. Processing $R C$ and Extraction. The processed RC was carried out according to the method described in Chinese Pharmacopoeia. Briefly, $10 \mathrm{~g}$ of $\mathrm{RC}$ was immersed in a beaker $(50 \mathrm{~mL})$ with acetic acid solution $(30 \mathrm{~mL}, 36 \%)$. The solution was heated until dryness. Then the processed $\mathrm{RC}$ was extracted in Soxhlet extractor with $150 \mathrm{~mL}$ of $\mathrm{MeOH} / \mathrm{H}_{2} \mathrm{O}$ $(4 / 1 ; \mathrm{V} / \mathrm{V})$ until the extracting solution was colorless. After getting rid of the methanol by water bathing, the residual extracting solution $(30 \mathrm{~mL})$ was added to isopycnic $\mathrm{HCl}$ 


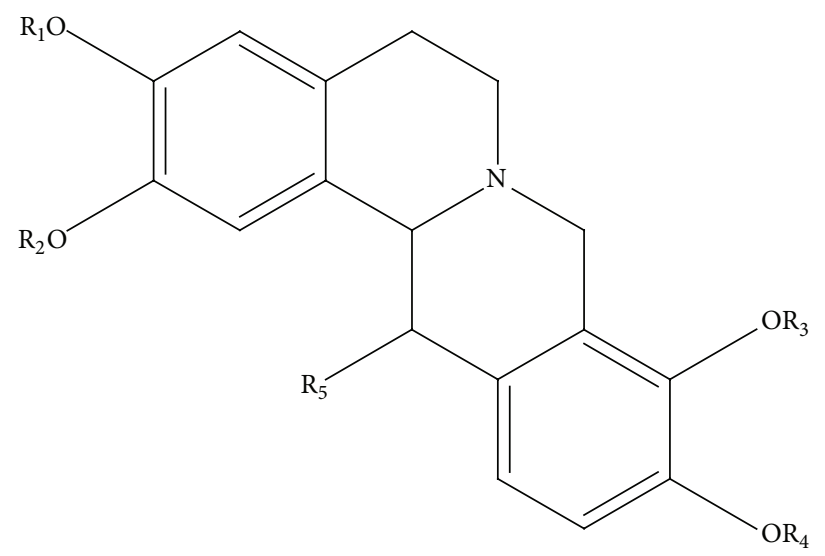

(a)

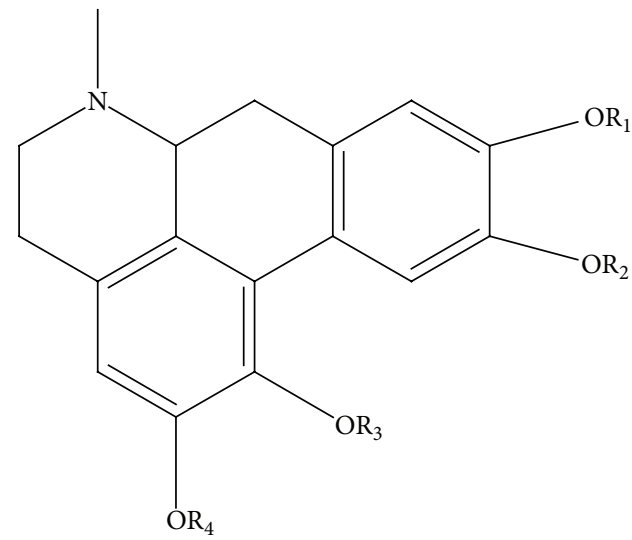

(b)

Figure 2: Two foundation formations of alkaloids in Rhizoma Corydalis. (a) Corydaline: $\mathrm{R}_{1}=\mathrm{R}_{2}=\mathrm{R}_{3}=\mathrm{R}_{4}=\mathrm{CH}_{3}$. Thalictricavine: $\mathrm{R}_{1}+\mathrm{R}_{2}=-$ $\mathrm{CH}_{2}-; \mathrm{R}_{3}=\mathrm{R}_{4}=\mathrm{CH}_{3}$.

TABLE 1: Alkaloids identified from processed RC and RC by mass spectrum.

\begin{tabular}{|c|c|c|c|c|}
\hline Peaks & Retention time & Compounds & Match degree & Sample source \\
\hline 1 & 20.288 & $\begin{array}{l}\text { 4b,5,10,10a,11,-12-Hexahydro-3-hydroxy-2,8,9-tri(methoxy) } \\
\text { Isoquino [2.1-b] isoquinoline }\end{array}$ & 90 & (2) \\
\hline 2 & 25.771 & N-Methyllaurotetanine & 81 & (2) \\
\hline 3 & 26.158 & Glaucine & 78 & \\
\hline 4 & 26.420 & (+)-Corydaline $\quad 178 \quad 355369$ & - & (2), (3) \\
\hline 5 & 26.485 & (+)-Corydaline $\quad 178 \quad 369$ & - & (1) \\
\hline 6 & 26.668 & $\begin{array}{l}\text { (13S.13aR)-2,3-Dioxhydryl-9,13-methyl-10-ethyl-6,8.13,13a- } \\
\text { tetrahydro-5H-isoquinolino[2,1-b]isoquinoline } \\
\mathrm{R}_{1}=\mathrm{R}_{2}=\mathrm{H}, \mathrm{R}_{3}=\mathrm{CH}_{3}, \mathrm{R}_{4}=\mathrm{C}_{2} \mathrm{H}_{5}, \mathrm{R}_{5}=\mathrm{CH}_{3} \quad \text { 192, } 355 \\
\text { (13S.13aR)-2,3-(Methylenedioxy)-9,10-dimethoxy-13-methyl- }\end{array}$ & - & (2) \\
\hline 7 & 26.936 & $\begin{array}{l}\text { (13S.13aR)-2,3-(Methylenedioxy)-9,10-dimethoxy-13-methyl- } \\
\text { 6,8.13,13a-tetrahydro-5H-isoquinolino[2,1-b] isoquinoline } \\
\mathrm{R}_{1}+\mathrm{R}_{2}=-\mathrm{CH}_{2}-, \mathrm{R}_{3}=\mathrm{R}_{4}=\mathrm{R}_{5}=\mathrm{CH}_{3} \quad 178 \quad 355\end{array}$ & - & (2) \\
\hline 8 & 27.076 & $(+)$-Canadine $\mathrm{C}_{20} \mathrm{H}_{21} \mathrm{O}_{4} \mathrm{~N}$ & 76 & (3) \\
\hline 9 & 27.425 & Protopine & 90 & (3) \\
\hline 10 & 27.468 & $\begin{array}{l}\text { 6H-Dibenzo[a,g] quinolizine, } \\
5,8,13,13 \text { a-tetrahydro-2,3,10,11-tetramethoxy } \\
\mathrm{R}_{1}=\mathrm{R}_{2}=\mathrm{R}_{3}=\mathrm{R}_{4}=\mathrm{CH}_{3}, \mathrm{R}_{5}=\mathrm{H} \quad 164,192 \quad 355\end{array}$ & 84 & (2), (3) \\
\hline 11 & 27.741 & 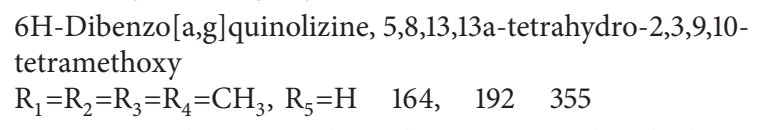 & 83 & (2), (3) \\
\hline 12 & 28.257 & $\begin{array}{l}\text { Isoquino [2.1-b] isoquinoline, } 4 \mathrm{~b}, 5,10,10 \mathrm{a}, 11,12 \text {-hexahydro-2- } \\
\text { hydroxy-3,8,9-trismethoxy- } \mathrm{C}_{20} \mathrm{H}_{23} \mathrm{O}_{4} \mathrm{~N}\end{array}$ & 92 & (2), (3) \\
\hline 13 & 29.041 & Isocorydine $\mathrm{C}_{20} \mathrm{H}_{23} \mathrm{O}_{4} \mathrm{~N} \quad 341$ & 64 & (2) \\
\hline
\end{tabular}

“_": identified by artificial analysis.

Sample source: (1) the processed Rhizoma Corydalis sample extracted with methanol, (2) the crude Rhizoma Corydalis sample extracted with methanol, and (3) the crude Rhizoma Corydalis sample extracted with acetone.

solution $(12 \mathrm{~mol} / \mathrm{L})$. The mixture $(60 \mathrm{~mL})$ was refluxed for $1 \mathrm{~h}$ and extracted with dichloromethane $(20 \mathrm{~mL} \times 3)$ in a separatory funnel to be degreased after cooling to room temperature. The degreased solution $(60 \mathrm{~mL})$ was filtered after adjusting the $\mathrm{pH}$ to 8 with $\mathrm{NaOH}$. The filtrate $(60 \mathrm{~mL})$ was extracted with dichloromethane $(20 \mathrm{~mL} \times 3)$. The organic phase was collected in a conical flask. $10 \mathrm{~mL}$ of the organic phase was transferred to a tube $(10 \mathrm{~mL})$ and evaporated to dryness under a $\mathrm{N}_{2}$ stream. The residue was dissolved with $1.0 \mathrm{~mL}$ of acetone, marked $\mathrm{S} 1$, and then stored in $-20^{\circ} \mathrm{C}$ for further GC/MS analysis.

The extractions of the crude RC with methanol and acetone were the same as described above except that the drug had not undergone processing. The methanol and acetone extracts of RC were marked S2 and S3, respectively, and stored in $-20^{\circ} \mathrm{C}$ for further GC/MS analysis. 
TABLE 2: The relative contents of alkaloids in the crude RC samples $\mathrm{S} 2$ and $\mathrm{S} 3$.

\begin{tabular}{lcc}
\hline $\begin{array}{l}\text { Alkaloids and } \\
\text { retention time }\end{array}$ & $\begin{array}{c}\text { Relative contents } \\
(\mathrm{S} 2, \%)\end{array}$ & $\begin{array}{c}\text { Relative contents } \\
(\mathrm{S} 3, \%)\end{array}$ \\
\hline $1^{\#}(20.288)$ & 1.36 & 0.61 \\
$2^{\#}(25.771)$ & 6.21 & 4.31 \\
$4^{\#}(26.420)$ & 7.61 & 13.15 \\
$6^{\#}(26.668)$ & 12.64 & 16.05 \\
$7^{\#}(26.936)$ & 5.63 & 5.03 \\
$8^{\#}(27.076)$ & - & 3.82 \\
$10^{\#}(27.468)$ & 30.16 & 26.18 \\
$11^{\#}(27.741)$ & 7.83 & 10.38 \\
$12^{\#}(28.257)$ & 22.12 & 16.36 \\
$13^{\#}(29.041)$ & 6.43 & 4.10 \\
\hline
\end{tabular}

The numbers of alkaloids $\left(X^{\#}\right)$ were consistent with those in Table 1.

2.3. GC/MS Analysis. GC/MS was performed on an Agilent 7890A GC Plus equipped with an 5975C mass/selective detector (Agilent Technologies). A fuse silica capillary column, HP-5-MS, with 5\%-phenyl methylpolysiloxane as nopolar stationary phase $(30 \mathrm{~m} \times 0.25 \mathrm{~mm}$ i.d. $\times 0.25 \mathrm{~mm}$ film thickness, Agilent Technologies) was utilized for analysis of alkaloids obtained from the processed $\mathrm{RC}$ and the crude RC. The injection port temperature was $260^{\circ} \mathrm{C}$. The column temperature programme started at $40^{\circ} \mathrm{C}$ upon injection. The temperature was increased at a rate of $40^{\circ} \mathrm{C} / \mathrm{min}$ to $110^{\circ} \mathrm{C}$ and then at a rate of $8^{\circ} \mathrm{C} / \mathrm{min}$ to $260^{\circ} \mathrm{C}$ and held there for $10 \mathrm{~min}$. Purified helium gas at a flow rate of $1 \mathrm{~mL} / \mathrm{min}$ was used as the GC carrier gas in constant flow fashion. Each sample $(1 \mu \mathrm{L})$ was injected into the column using a $60: 1$ split injection and solvent delay time was $3 \mathrm{~min}$. The mass spectrometer was operated in the electron impact (EI) mode with an electron energy of $70 \mathrm{eV}$; ion source temperature, $230^{\circ} \mathrm{C}$; quadrupole temperature, $150^{\circ} \mathrm{C}$; mass range, $\mathrm{m} / \mathrm{z} 38-550$; scan rate, $0.25 \mathrm{~s} / \mathrm{scan}$; EM voltage, $1423 \mathrm{~V}$; and the GC/MS transfer line was set to $280^{\circ} \mathrm{C}$.

\section{Results and Discussion}

3.1. Chromatographic Separation. The processed RC sample was claybank via extraction in Soxhlet extractor and the crude RC samples were faint yellow. An important feature is the cleanup of samples prior to GC/MS analysis because the presence of matrix interference leads to ion suppression or enhancement in many cases $[25,26]$. After degreasing, alkaloids were enriched and most micromolecules were wiped off.

Figure 1 was the chromatograms of three samples after $19 \mathrm{~min}$. The chromatographic distillate components before 19 min (not shown in Figure 1) are the constituents with low boiling point like alkane, ester, alcohol, ketone, and fatty acid, which are the residual in the degreased process. The alkaloids, however, with higher boiling points and lower vapor pressures were eluted after $19 \mathrm{~min}$. As Figure 1 showed, the components of S1 eluted after 19 min are less than those of S2 and S3 obviously.
More than ten peaks were eluted after $19 \mathrm{~min}$ from the crude samples S2 and S3. The retention times of the peaks were the same but the heights of peaks were not equal due to the different concentration between S2 and S3, whereas there were only a few peaks eluted from S1. The processed sample S1 had obvious differences to the crude samples S2 and S3, which indicated that the constituents with high boiling point eluted after $19 \mathrm{~min}$ were related more to the processing of the sample rather than to the extraction solvent, which led to content changes and chemical rearrangements of alkaloid components.

3.2. Identification of Alkaloids. The identifications of the alkaloid components were based on computer matching of their mass spectral fragmentation patterns with those stored in the spectrometer database using the National Institute of Standards and Technology Mass Spectral Database (NISTMS, 2008) and artificial interpreting of their fragmentation patterns. Table 1 showed that a total of 13 kinds of alkaloids including corydaline, glaucine, canadine, and protopine were identified from the crude and processed RC samples. They have two backbone structures to constitute two series of alkaloids (Figure 2). Among them, there were two chromatographic peaks (retention times 20.288 and 28.257) with extremely similar mass spectral fragmentation, hence with the same searching result. The latter peak (28.257) with higher match degree was identified as the search result Isoquino [2.1-b] isoquinoline, 4b,5,10,10a,11,12-hexahydro-2-hydroxy3,8,9-trismethoxy-, and the former peak was identified as isomer of the latter.

There was no matching with corydaline in Mass Spectral Database (NIST-MS, 2008). The mass spectral data of corydaline were mostly carried out using ESI model due to the poor volatilization of corydaline. With rare fragment ion, the ESI mass spectrum was not equipped with mass spectral database. Hence, ESI mass spectral data was not identified through mass spectral library search. Fortunately, Rueffer et al. [12] had performed the study to probe into a biosynthesis path of these alkaloids using $\mathrm{C} 13$ markers, in which themass spectrum ofthalictricavine, very similar to corydaline, was provided using EI model (Figure 3(a)). It indicated that the based fragment ion was $\mathrm{m} / z 178$ (base peak) which was cleaved from piperidine (Figure 3(b)). Figure 4 was the mass spectrum (EI) of chromatographic peak $\mathrm{P}_{4}(26.426)$ and $\mathrm{P}_{5}$ (26.485). As Figure 4 showed that the base peak of mass spectrum for both $\mathrm{P}_{4}$ and $\mathrm{P}_{5}$ is $m / z 178$ and the second base peaks are different, $\mathrm{P}_{4}$ is $m / z 355$, not the molecule ion, and $\mathrm{P}_{5}$ is $m / z 369$, the molecule ion. The compound of $\mathrm{P} 4$ was identified as corydaline according to the research by Rueffer et al. [12]. And the $\mathrm{P}_{5}$ was identified as conformational isomer of corydaline. This outcome was backed not only by mass spectral data but also by the retention time. The difference of retention time between two peaks was about $3.6 \mathrm{~s}$. It indicated that conformational change happened with corydaline when the $\mathrm{RC}$ was processed. A simple acid bath of RC was capable of the conformation conversion of corydaline, which illustrated that the threshold battery of conformation conversion for 


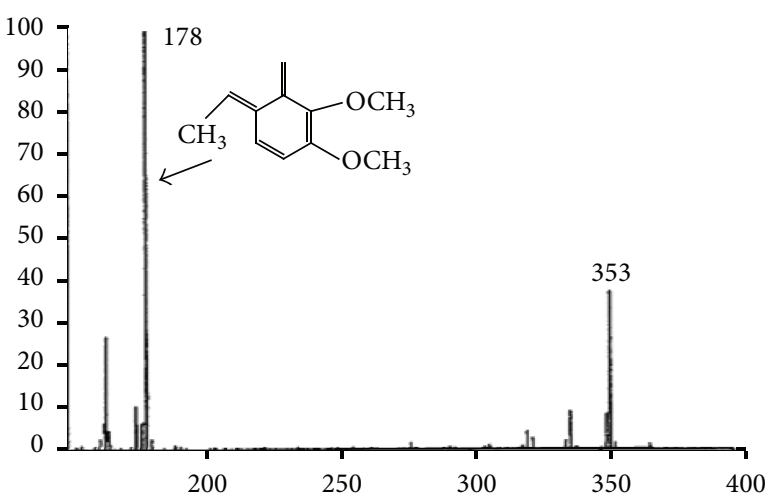

(a)<smiles>C=c1c(OC)c(OC)ccc1=CCCCCc1ccc(OC)c(OC)c1CN1CCc2cc(OC)c(OC)cc2C1C</smiles>

(b)

FIGURE 3: The mass spectrum (EI) of thalictricavine and fragmentation pathway of (+)-corydaline. (a) The mass spectrum of thalictricavine was performed by Rueffer et al.

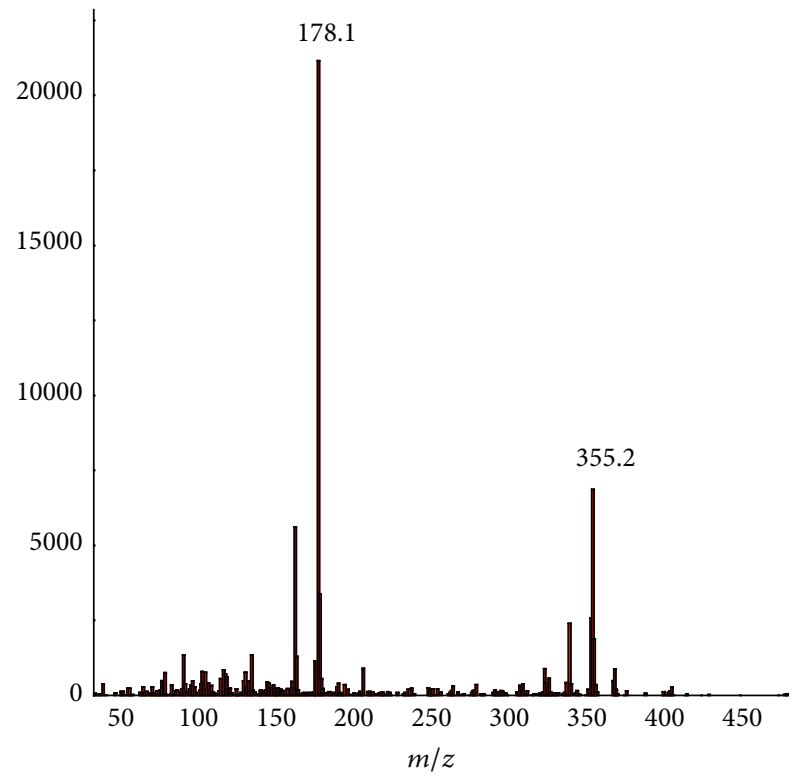

(a)

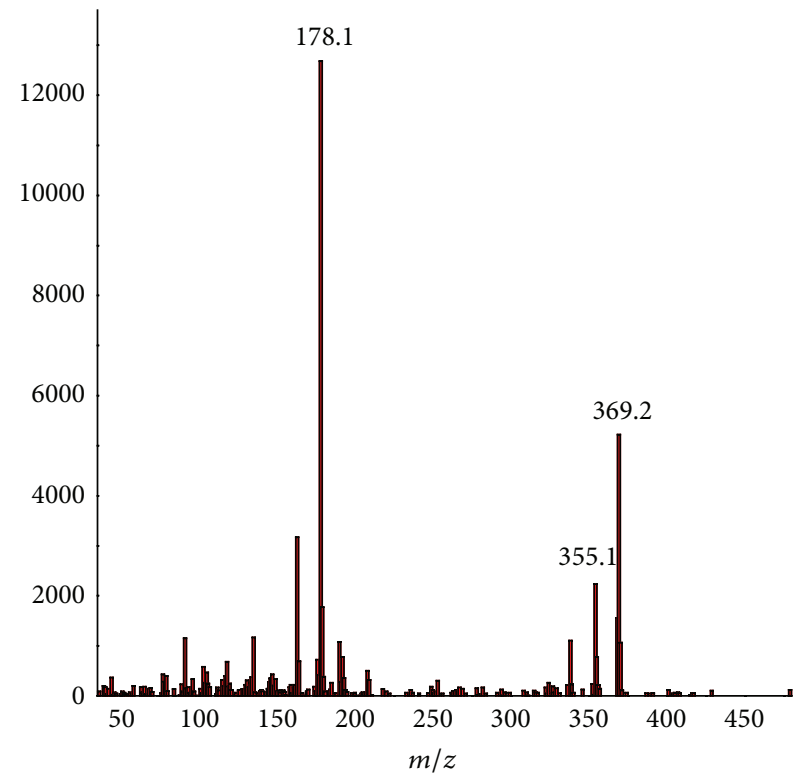

(b)

Figure 4: Mass spectrum (EI) of peak of $\mathrm{P}_{4}(\mathrm{a})$ and $\mathrm{P}_{5}$ (b).

corydaline was low; and the traditional processing herbal medicine procedure was efficient in reducing their toxicity.

\subsection{Effect of Different Solvents on Extraction of Alkaloid.} Although GC/MS total ion chromatograms (after $19 \mathrm{~min}$ ) of crude CR samples S2 and S3 were similar to each other, the relative content of component was different. Table 2 was the relative contents of alkaloids in the crude RC samples S2 and S3. The contents of eluted alkaloids in S2 were higher than those in S3 except 4, 6, and 11\# peaks. It suggested that extraction solvent was dependent on the target alkaloids. The most relative content component in S2 and S3 was $10 \#$ peak, which was not fully separated and contained two components. It indicated that the chromatographic behavior of these components was very similar. The different oven programs were performed to improve their separation, but the outcome was not as expected.

\section{Conclusion}

The crude RC and processed RC were qualitatively and semiquantitatively analyzed using gas chromatography-mass spectrometry (GC/MS) method. The totals of 13 kinds of alkaloids were identified, in which 11 kinds of alkaloids were from the crude RC sample and two were from the processed RC sample. The 13 kinds of alkaloids are all from two backbone structures forming two series of alkaloids. The extraction of alkaloids was related a little to the solvent used. Most of the alkaloids in crude RC were not detected and the corydaline had been changed in conformation after the $\mathrm{RC}$ had undergone processing, which provided support for 
the conclusion of reducing toxicity in the traditional drugs treatment process.

\section{Conflict of Interests}

The authors declare that there is no conflict of interests regarding the publication of this paper.

\section{References}

[1] Sate Administration of Traditional Chinese Medicine of the People's Republic of China, Dictionary of Traditional Chinese Medicine, Shanghai Science and Technology Press, Shanghai, China, 2002.

[2] L. R. Song, Dictionary of Modern Medicine, People's Medical Publishing House, 2001.

[3] Q. Min, Y. T. Bai, and S. J. Shu, "Protective effect of dltetrahydropalmatine on liver injury induced by carbon tetrachloride in mice," China Journal of Chinese Materia Medica, vol. 31, no. 6, pp. 483-484, 2006.

[4] M.-T. Lin, F.-Y. Chueh, and M.-T. Hsich, "The hypothermic effects of dl-tetrahydropalmatine in rats," Neuroscience Letters, vol. 315, no. 1-2, pp. 53-56, 2001.

[5] C.-L. Hsieh, E.-T. Liao, S.-Y. Chiang, C.-J. Lao, N.-Y. Tang, and J.-T. Lin, "Effect of Rhizoma Corydalis on focal cerebral infarct in ischemia-reperfusion injured rats," Acta Pharmacologica Sinica, vol. 22, no. 12, pp. 1143-1148, 2001.

[6] L. He and G. Q. Liu, "Interaction of multidrug resistance reversal agents with P-glycoprotein ATPase activity on bloodbrain barrier," Acta Pharmacologica Sinica, vol. 23, no. 5, pp. 423-429, 2002.

[7] J. F. Wang, L. S. Liang, Q. Y. Zhang, X. G. Li, and Z. J. Fu, "Preclinical pharmacokinetics, tissue distribution and excretion studies of a potential analgesics-corydaline using an ultra performance liquid chromatography-tandem mass spectrometry," Journal of Chromatography B, vol. 942-943, pp. 70-76, 2013.

[8] S. Naruto and H. Kaneko, "Alkaloids from Corydalis ambigua," Phytochemistry, vol. 12, no. 12, pp. 3008-3009, 1973.

[9] B. Ding, T. T. Zhou, G. R. Fan, and Z. Y. Hong, "Qualitative and quantitative determination of ten alkaloids in traditional Chinese medicine Corydalis yanhusuo W.T. Wang by LCMS/MS and LC-DAD," Journal of Pharmaceutical and Biomedical Analysis, vol. 45, no. 2, pp. 219-221, 2007.

[10] S. Sturm, C. Seger, M. Godejohann, M. Spraul, and H. Stuppner, "Conventional sample enrichment strategies combined with high-performance liquid chromatography-solid phase extraction-nuclear magnetic resonance analysis allows analyte identification from a single minuscule Corydalis solida plant tuber," Journal of Chromatography A, vol. 1163, no. 1-2, pp. 138144, 2007.

[11] L. Grycováa, J. Dostálc, and R. Marek, "Quaternary protoberberine alkaloids," Phytochemistry, vol. 68, no. 2, pp. 150-175, 2007.

[12] M. Rueffer, W. Bauer, and M. H. Zenk, "The formation of corydaline and related alkaloids in Corydalis cava in vivo and in vitro," Canadian Journal of Chemistry, vol. 72, no. 1, pp. 170-175, 1994.

[13] G. J. van Berkel, B. A. Tomkins, and V. Kertesz, "Thinlayer chromatography/desorption electrospray ionization mass spectrometry: investigation of goldenseal alkaloids," Analytical Chemistry, vol. 79, no. 7, pp. 2778-2789, 2007.

[14] Y. F. Yuan, X. L. Li, Z. L. Liu, L. F. Shi, L. Li, and Y. H. Li, "Analysis of dl-tetrahydropalmatine in corydalis yanhusuo W. T. Wang by supercritical fluid extraction and HPLC," Acta Pharmaceutica Sinica, vol. 31, no. 4, p. 282, 1996.

[15] Y. Tao, H. Y. Xu, S. S. Wang et al., "Identification of the absorbed constituents after oral administration of Yuanhu Zhitong prescription extract and its pharmacokinetic study by rapid resolution liquid chromatography/quadrupole time-offlight," Journal of Chromatography B, vol. 935, pp. 1-9, 2013.

[16] S. Sturm, C. Seger, and H. Stupper, "Analysis of Central European Corydalis species by nonaqueous capillary electrophoresis-electrospray ion trap mass spectrometry," Journal of Chromatography A, vol. 1159, no. 1, pp. 42-44, 2007.

[17] L. T. Taylor, "Supercritical fluid chromatography," Analytical Chemistry, vol. 80, no. 12, pp. 4285-4294, 2008.

[18] C. Guo, Y. Jiang, L. Li et al., "Application of a liquid chromatography-tandem mass spectrometry method to the pharmacokinetics, tissue distribution and excretion studies of Dactylicapnos scandens in rats," Journal of Pharmaceutical and Biomedical Analysis, vol. 74, pp. 92-100, 2013.

[19] Y. C. Zhang, H. Y. Xu, X. M. Chen et al., "Simultaneous quantification of 17 constituents from Yuanhu Zhitong tablet using rapid resolution liquid chromatography coupled with a triple quadrupole electrospray tandem mass spectrometry," Journal of Pharmaceutical and Biomedical Analysis, vol. 56, no. 3, pp. 497-504, 2011.

[20] J. Zhang, Y. Jin, J. Dong et al., "Systematic screening and characterization of tertiary and quaternary alkaloids from corydalis yanhusuo W.T. Wang using ultra-performance liquid chromatography-quadrupole-time-of-flight mass spectrometry," Talanta, vol. 78, no. 2, pp. 513-522, 2009.

[21] J. G. Lisko, S. B. Stanfill, B. W. Duncan, and C. H. Watson, "Application of GC-MS/MS for the analysis of tobacco alkaloids in cigarette filler and various tobacco species," Analytical Chemistry, vol. 85, no. 6, pp. 3380-3384, 2013.

[22] S. Tian, X. Mao, S. Miao, Z. Jia, K. Wang, and S. Ji, "Determination of seven toxaphene congeners in ginseng and milkvetch root by gas chromatography-tandem mass spectrometry," Chinese Journal of Chromatography, vol. 30, no. 1, pp. 14-20, 2012.

[23] G. Boschin, P. Annicchiarico, D. Resta, A. D'Agostina, and A. Arnoldi, "Quinolizidine alkaloids in seeds of lupin genotypes of different origins," Journal of Agricultural and Food Chemistry, vol. 56, no. 10, pp. 3657-3663, 2008.

[24] Pharmacopoeia Commission of Ministry of health of the People's Republic of China, Chinese Pharmacopoeia, Appendix15, People's Medical Publishing House, 1995.

[25] B. K. Matuszewski, M. L. Constanzer, and C. M. Chavez-Eng, "Strategies for the assessment of matrix effect in quantitative bioanalytical methods based on HPLC-MS/MS," Analytical Chemistry, vol. 75, no. 13, pp. 3019-3030, 2003.

[26] F. Gosetti, E. Mazzucco, D. Zampieri, and M. C. Gennaro, "Signal suppression/enhancement in high-performance liquid chromatography tandem mass spectrometry," Journal of Chromatography A, vol. 1217, no. 25, pp. 3929-3937, 2010. 

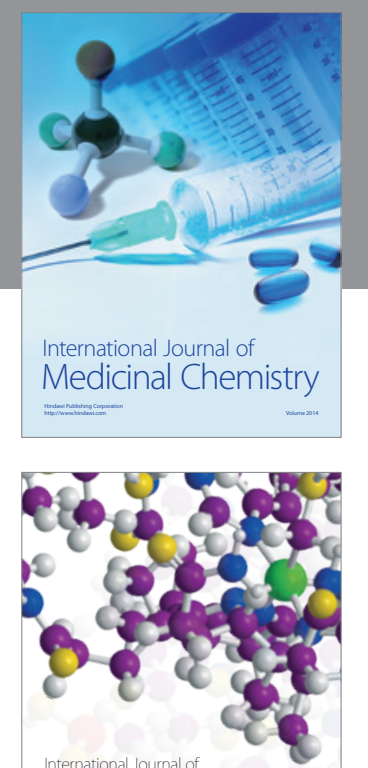

\section{Carbohydrate} Chemistry

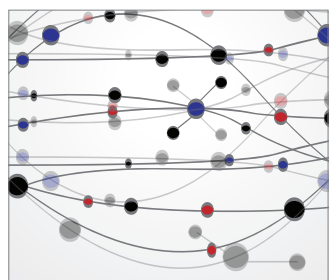

The Scientific World Journal
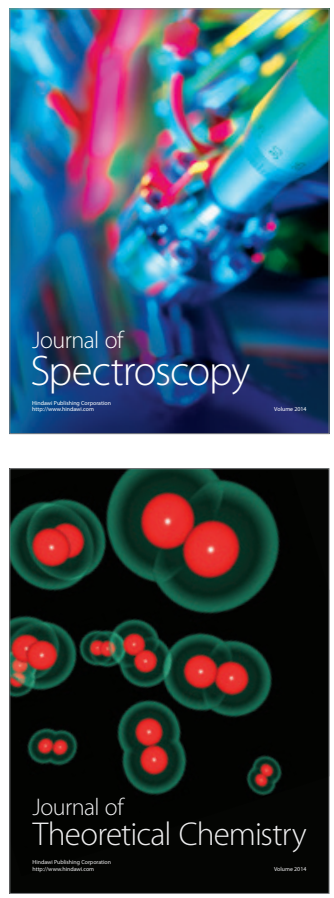
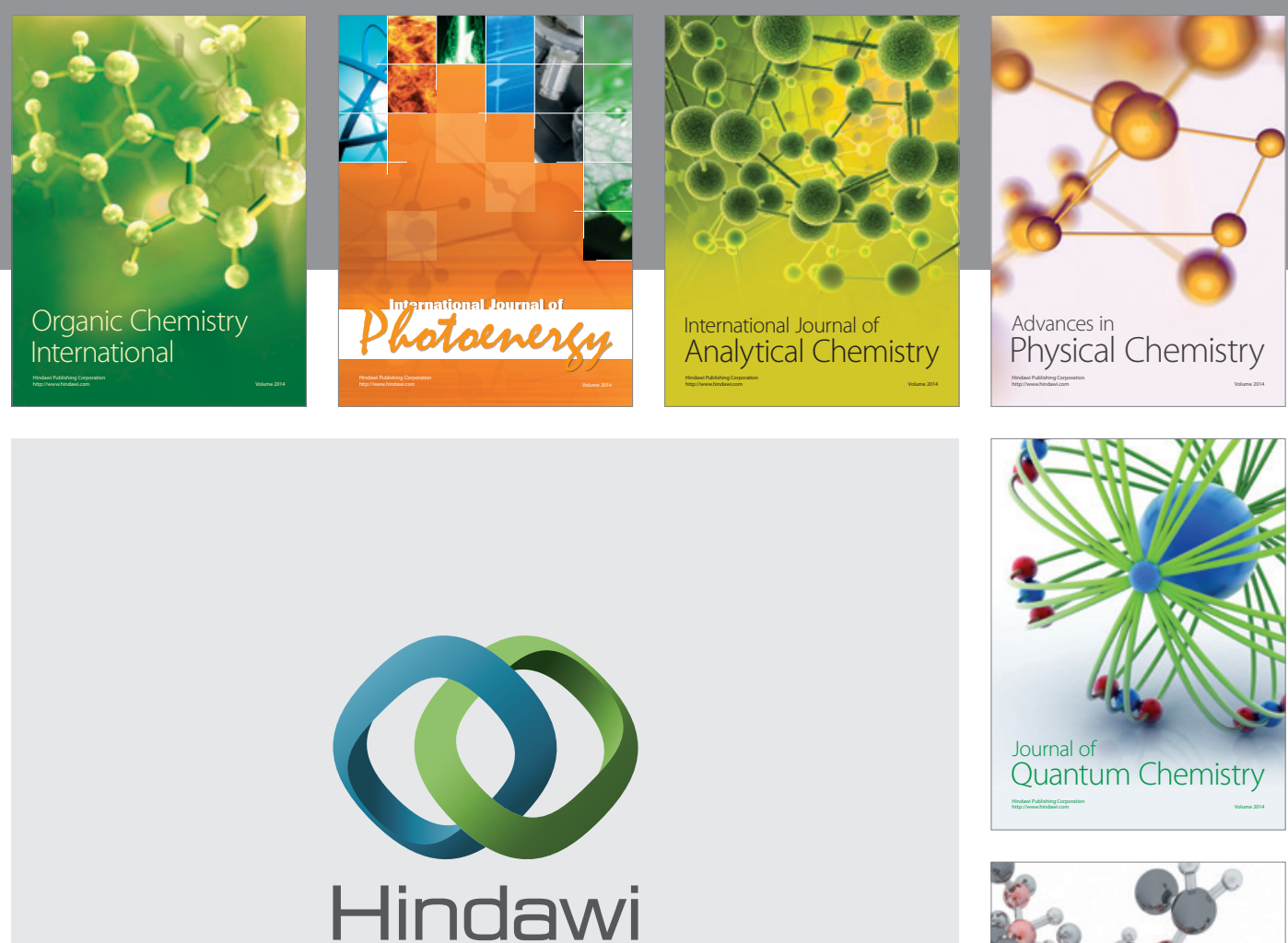

Submit your manuscripts at

http://www.hindawi.com

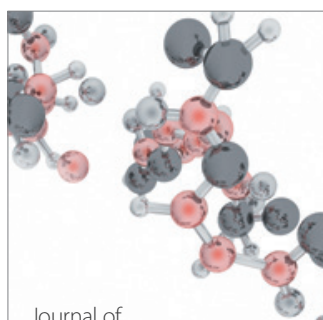

Analytical Methods

in Chemistry

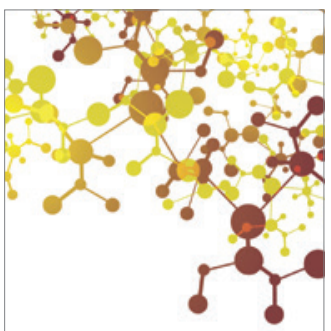

Journal of

Applied Chemistry

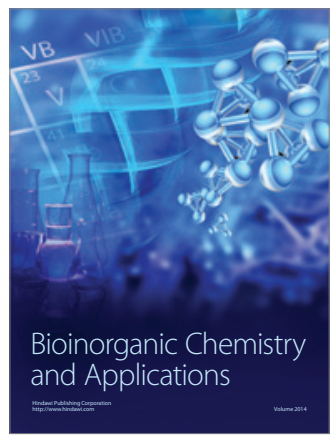

Inorganic Chemistry
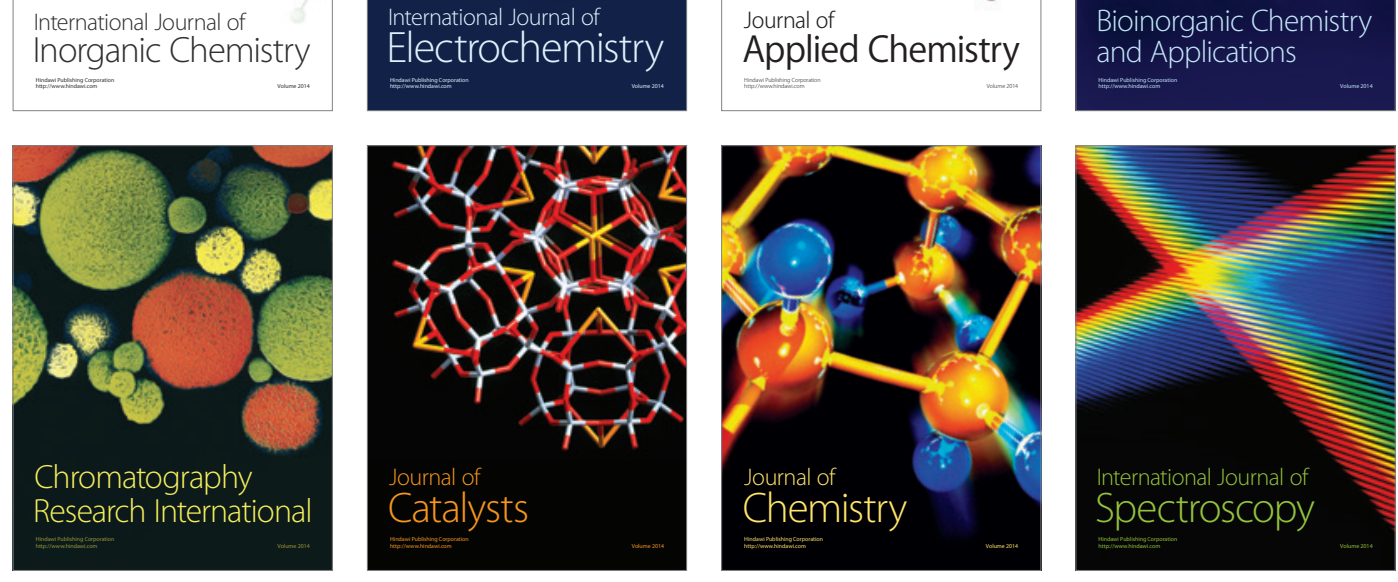